\title{
Effects of Cold Treatments on Seedling Emergence and Growth of Lilium davidii var. unicolor Bulblets
}

\author{
Nan Tang \\ Key Laboratory of Qinghai Province for Landscape Plants Research/Plateau \\ Flower Research Centre, Qinghai University, Xining 810016, China; and State \\ Key Laboratory of Plateau Ecology and Agriculture, Qinghai University, \\ Xining 810016, China \\ Rulong Jia, Jicheng Yin, Yan Wang, and Daocheng Tang \\ Key Laboratory of Qinghai Province for Landscape Plants Research/Plateau \\ Flower Research Centre, Qinghai University, Xining 810016, China
}

Additional index words. chilling treatment, germination, Lanzhou lily, vegetative propagation

\begin{abstract}
For Lilium davidii var. unicolor bulblets produced by scale propagation, the effects of cold treatments on the sprouting and development of bulblets were studied. The results showed that $5^{\circ} \mathrm{C}$ was a more suitable temperature than 2 or $10{ }^{\circ} \mathrm{C}$. Bulblets treated at $5{ }^{\circ} \mathrm{C}$ for 3 weeks presented the best uniformity of seedling emergence, and the sprouting rate was $100 \%$. Moreover, the largest bulbs were observed in this treatment after a growing season. It was found that long storage at low temperatures is unfavorable for bulb development. The weight and circumference of bulbs from bulblets that were cold-treated for more than 5 weeks were significantly less than those treated for 1 to 4 weeks. During the first 4 weeks of cold storage, the starch content of bulblets decreased significantly, coinciding with an increase in soluble sugars. The starch and soluble sugar contents in bulblets stored at 2 and $5{ }^{\circ} \mathrm{C}$ changed faster than those in bulblets stored at $10^{\circ} \mathrm{C}$. However, the effect of temperature on carbohydrates diminished gradually as the storage time increased. Long storage of bulblets at low temperatures is not good for subsequent growth and development. The results of this study provide important information for accelerating the scale propagation of $L$. davidii var. unicolor and maximizing bulb yield.
\end{abstract}

Lilium davidii var. unicolor, a variety of Lilium davidii Elwes, is an important bulbous plant not only for its beautiful flowers, but also for its edible bulbs. It has a long history of being used as a vegetable in China. The bulbs taste sweet and can be eaten fresh or cooked. Bulbs are a healthy food that helps strengthen people's immune system because the bulbs are rich in starch, dietary fiber, vitamins, and a variety of bioactive substances, such as polysaccharides, alkaloids, and saponins (You et al., 2010; Zhang et al., 2010). Moreover, bulbs have been suggested to be useful in relieving pulmonaryrelated diseases such as cough and phlegm, and could be used as a therapeutic candidate for pulmonary inflammation caused by cigarette smoke (Lee et al., 2013; Li et al., 2021).

Among the reproduction methods of lilies, scale propagation is preferred because it is the

Received for publication 26 Apr. 2021. Accepted for publication 24 June 2021.

Published online 16 August 2021.

We are thankful for the foundation from the Science and Technology Department of Qinghai Province (2018-NK-102). We are also grateful for the support from project Integration and Commercialization of Research Findings on Propagation of Excellent Bulb for Edible Lily (2021ZY025).

D.T. is the corresponding author. E-mail: 2010990004@qhu.edu.cn.

This is an open access article distributed under the CC BY-NC-ND license (https://creativecommons. org/licenses/by-nc-nd/4.0/) most cost-effective and time-saving approach in the large-scale production of bulbs (Matsuo and van Tuyl, 1984; Matsuo et al., 1989; Tang et al., 2020). A large number of bulblets can be obtained through scale propagation. In research on bulblet differentiation after scale propagation of L. longiflorum, it was found that 1.2 to 2.6 bulblets per scale were obtained from external to internal scales (Marinangeli et al., 2003). Our previous research showed that scales of $L$. davidii cultivated at $30^{\circ} \mathrm{C}$ could produce approximately two bulblets per scale, and the propagation coefficient per bulb could reach 111.9 (Jia et al., 2020). After the production of bulblets, successful sprouting and growth becomes the key issue for further bulb production. The developmental state of the bulblet, bulblet size, and degree of dormancy were considered three factors with a major influence on the growth of the bulblets (Langens-Gerrits et al., 2003). Bulbs of lilies develop dormancy to survive unfavorable environments. Bulbs can sprout and grow under suitable environmental conditions after dormancy is broken (Xu et al., 2006). Temperature, carbohydrates, and hormones are the main factors involved in the development of dormancy (Delvallée et al., 1990). Many studies have reported the conversion of carbohydrates, and variations in hormones and related enzymes during dormancy development (Djilianov et al., 1994; Liu et al., 2014; Xu et al., 2006).

Because the growth cycle of the lily requires a cold-warm-cold temperature change (Zhou et al., 2021), bulblets generated on scales may develop dormancy depending on the culture conditions (Delvallée et al., 1990). Cold treatment can break the dormancy of lily bulblets, which leads to sprouting and plant development (Shin et al., 2002). Normally, $5^{\circ} \mathrm{C}$ can break dormancy effectively for many geophytes, including lily (Dole, 2003). However, the response of plants to low temperatures varies greatly as a result of differences in species, cultivar, plant maturity, cultivation method, and environmental conditions (Erwin and EngelenEigles, 1998; Kawarabayashi, 2015; Lee et al., 1996). Langens-Gerrits et al. (2003) studied the effect of low temperature on sprouting, time of leaf emergence, and bulb growth of lily bulblets generated in vitro. Micropropagated bulblets of L. speciosum planted at $15^{\circ} \mathrm{C}$ showed a greater sprouting percentage than those planted at 20 and $25^{\circ} \mathrm{C}$ (de Klerk and Paffen, 1995).

When bulblets that are generated on scales are planted in soil, the major problems are low emergence rate and seedling uniformity. In our study, we investigated the effect of different temperatures and treatment durations on the sprouting of bulblets, and bulb growth was assessed after a growing season. This study aimed to screen the best temperature treatment for bulblets of $L$. davidii produced by scale propagation that resulted in maximum sprouting under a minimum storage time and that produced the largest bulbs. The results of this study will provide theoretical and technical support for bulb production of L. davidii var. unicolor by scale propagation.

\section{Materials and Methods}

Plant materials. Bulbs of $L$. davidii var. unicolor were used for producing bulblets by means of scale propagation. Fresh bulbs (150 \pm $10 \mathrm{~g}$ ) were collected in Mar. 2019 from a field at the Plateau Flower Research Center of Qinghai University, Qinghai Province, China (lat. $36^{\circ} 43^{\prime} 32^{\prime \prime} \mathrm{N}$, long. $101^{\circ} 45^{\prime} 2 " \mathrm{E}$; elevation, 2320 $\mathrm{m})$. Bulbs were placed at room temperature for 1 week before they were used for scale propagation. Scales were removed from healthy bulbs, washed in tap water, and immersed in $0.5 \%$ thiophanate-methyl for 30 minutes. Scales that had mechanical damage were removed. Peat (Floragard, Niedersachsen, Germany) was sterilized with $125 \times$ formaldehyde and $50 \%$ thiophanate-methyl $\left(100 \mathrm{~g} / \mathrm{m}^{3}\right)$. Then, scales were mixed with an equal volume of the prepared peat, placed in a propagation bed, and covered with $5 \mathrm{~cm}$ of sterilized peat. To preserve moisture, the bed was wrapped in a plastic film with holes. Scales were incubated at $30^{\circ} \mathrm{C}$. The temperature of the propagation bed was maintained using a heater wire and temperature controller. During incubation, bulblet growth was checked every week. After 6 weeks, bulblets were collected and graded according to their weight and size. Bulblets with a uniform size (circumference, $1.0 \pm 0.1 \mathrm{~cm}$; weight, $0.2 \pm$ $0.02 \mathrm{~g}$ ) were selected for further experiments.

Cold treatment of the bulblets. Effects of different cold treatments $\left(2,5\right.$, and $\left.10^{\circ} \mathrm{C}\right)$ on seedling sprouting and bulb growth of $L$. davidii var. unicolor were investigated in this 
study. Bulblets without cold treatment (room temperature, $20 \pm 2{ }^{\circ} \mathrm{C}$ ) were used as a control. Bulblets were stored at different temperatures for 8 weeks. Thirty bulblets were removed and planted in a crate $(60 \times 40 \times$ $18 \mathrm{~cm})$ every week. Three replicates were performed for each treatment. Plastic film with holes $(10 \times 40 \mathrm{~mm})$ was laid in the bottom of crates, which were then filled with peat. The bulblets were planted, covered with $3 \mathrm{~cm}$ peat, and then placed outdoors. The temperature was 9 to $18^{\circ} \mathrm{C}$, the relative humidity of the air was $45 \%$ to $70 \%$, the illumination intensity was $3 \times 10^{4}$ to $4 \times 10^{4}$ lux, and shading was used at noon. The moisture of the peat was kept at $\approx 50 \%$ to $60 \%$ during the growing process.

Carbohydrate metabolism. Every week, 30 bulblets were selected randomly from each treatment and pooled to determine the contents of soluble sugars and starch. The contents of starch and soluble sugars were determined using anthrone colorimetry and were estimated based on fresh weight (Jan and Roel, 1993). Three independent experiments were performed.

Data collection and statistical analyses. Sprouting of bulblets was recorded every day, and the rate of emergence was calculated. After a growing season, the weight and circumference of bulbs were measured for each crate. Analysis of variance was performed using PASW statistics 18, and significant differences between treatments were assessed using the least significant difference test at $P<0.05$.

\section{Results}

Effects of cold treatments on the time of sprouting. The different temperature treatments showed various influences on the days to final sprouting, but the initial emergence time was unaffected (Table 1). Bulblets without cold treatment showed slow and nonuniform sprouting that lasted for more than $56 \mathrm{~d}$. For bulblets stored at low temperatures, the days from planting to final sprouting were greatly shortened. Wide variation was observed for days to final sprouting among different cold treatments. Bulblets that were treated at $5{ }^{\circ} \mathrm{C}$ for 3 weeks finished their sprouting in $21 \mathrm{~d}$. The sprouting phase took 6 weeks to complete. Bulblets stored at $2{ }^{\circ} \mathrm{C}$ for 4 weeks finished sprouting in $20 \mathrm{~d}$. The sprouting phase took 7 weeks to complete. However, for bulblets treated at $10^{\circ} \mathrm{C}$, it took $29 \mathrm{~d}$ to finish sprouting, even if they were pretreated for 5 weeks. The total time spent sprouting was much longer for the $10^{\circ} \mathrm{C}$ treatment than that for the $5^{\circ} \mathrm{C}$ and $2{ }^{\circ} \mathrm{C}$ treatments. In conclusion, considering the time and uniformity of seedling emergence, the best temperature and storage time for bulblet pretreatment is $5^{\circ} \mathrm{C}$ and 3 weeks.

Effects of cold treatments on the sprouting rate. The sprouting rates for different temperature treatments are shown in Figs. 1 through 3 . In general, cold treatment significantly enhanced the sprouting percentage of $L$. davidii bulblets generated by scale propagation. Different temperatures and storage times
Table 1. Effects of low temperature and storage time on seedling sprouting.

\begin{tabular}{|c|c|c|c|c|c|c|}
\hline \multirow{2}{*}{$\begin{array}{l}\text { Duration of } \\
\text { cold treatment } \\
\text { (wk) }\end{array}$} & \multicolumn{2}{|c|}{ Sprouting time at $2{ }^{\circ} \mathrm{C}(\mathrm{d})$} & \multicolumn{2}{|c|}{ Sprouting time at $5^{\circ} \mathrm{C}(\mathrm{d})$} & \multicolumn{2}{|c|}{ Sprouting time at $10^{\circ} \mathrm{C}(\mathrm{d})$} \\
\hline & $\begin{array}{c}\text { First } \\
\text { sprouting }\end{array}$ & $\begin{array}{c}\text { Final } \\
\text { sprouting }\end{array}$ & $\begin{array}{c}\text { First } \\
\text { sprouting }\end{array}$ & $\begin{array}{c}\text { Final } \\
\text { sprouting }\end{array}$ & $\begin{array}{c}\text { First } \\
\text { sprouting }\end{array}$ & $\begin{array}{c}\text { Final } \\
\text { sprouting }\end{array}$ \\
\hline$\overline{0^{z}}$ & 6 & $>56$ & 6 & $>56$ & 6 & $>56$ \\
\hline 1 & 5 & $>56$ & 5 & 36 & 5 & $>56$ \\
\hline 2 & 8 & 42 & 4 & 35 & 5 & 50 \\
\hline 3 & 6 & 35 & 6 & 21 & 6 & 35 \\
\hline 4 & 6 & 20 & 6 & 22 & 7 & 34 \\
\hline 5 & 7 & 21 & 7 & 20 & 5 & 29 \\
\hline 6 & 7 & 21 & 5 & 20 & 5 & 27 \\
\hline 7 & 6 & 21 & 4 & 22 & 6 & 28 \\
\hline 8 & 6 & 23 & 6 & 21 & 5 & 28 \\
\hline
\end{tabular}

${ }^{\mathrm{z}}$ Bulblets without cold treatment. showed different influences. For bulblets without cold treatment, maximum sprouting (78.89\%) occurred at $35 \mathrm{~d}$ after cultivation. Under a constant $2{ }^{\circ} \mathrm{C}$ treatment, the bulblets presented different sprouting performance when the storage time was extended (Fig. 1). The maximum sprouting rate of bulblets stored for 1 week was $93.33 \%$, which occurred $35 \mathrm{~d}$ after planting. The percentage of emergence increased to $100 \%$ when the storage time of bulblets was more than 2 weeks. To reach the greatest sprouting rate $(100 \%)$, bulblets stored at $2{ }^{\circ} \mathrm{C}$ for 2 weeks and 3 weeks needed $49 \mathrm{~d}$ and $42 \mathrm{~d}$ to sprout, respectively. Four weeks was the optimum storage time for treatment at $2{ }^{\circ} \mathrm{C}$, because it took only $28 \mathrm{~d}$ for the emergence of all bulblets. However, sprouting uniformity did not improve with the extension of storage time. Bulblets needed 21 to $28 \mathrm{~d}$ to finish sprouting if the storage time was longer than 5 weeks, which indicates that the total time taken for seedling emergence was longer.

Bulblets treated at $5^{\circ} \mathrm{C}$ showed similar variation as those treated at $2^{\circ} \mathrm{C}$ (Fig. 2). On the seventh day after the bulblets were planted in soil, the sprouting percentages were $1.11 \%$ to $15.56 \%$ for different storage times. The emergence of seedlings increased dramatically after $7 \mathrm{~d}$ of planting. The greatest sprouting rate $(100 \%)$ was observed at $42 \mathrm{~d}$ for bulblets stored at $5{ }^{\circ} \mathrm{C}$ for 1 week and 2 weeks. However, only $21 \mathrm{~d}$ was needed for bulblets in the 3 -week treatment to reach the $100 \%$ sprouting percentage. Thus, 3 weeks was the best storage time for bulblets stored at $5^{\circ} \mathrm{C}$ when considering emergence performance.

At a constant $10^{\circ} \mathrm{C}$, the greatest sprouting rates of bulblets stored for 1 week and 2 weeks were $90 \%$ and $97.78 \%$, respectively. Compared with untreated bulblets, those stored in low-temperature treatment showed enhanced seedling emergence (Fig. 3). However, compared with bulblets at 2 and $5{ }^{\circ} \mathrm{C}$, bulblets at $10^{\circ} \mathrm{C}$ needed more time to sprout fully. For the $10^{\circ} \mathrm{C} / 3$-week and $10^{\circ} \mathrm{C} / 4$ week treatments, the maximum sprouting rate (100\%) occurred at $42 \mathrm{~d}$ and $35 \mathrm{~d}$ after planting, respectively.

Growth of bulblets after a growing season. Weight and circumference are important parameters in the evaluation of bulb growth. In our study, under the influence of low temperatures in the time range of 0 to 8 weeks, the variation in bulb weight and circumference was determined after a growing season for all treatments. Our results show that the storage time of the low-temperature treatment had a noticeable influence on bulb growth.

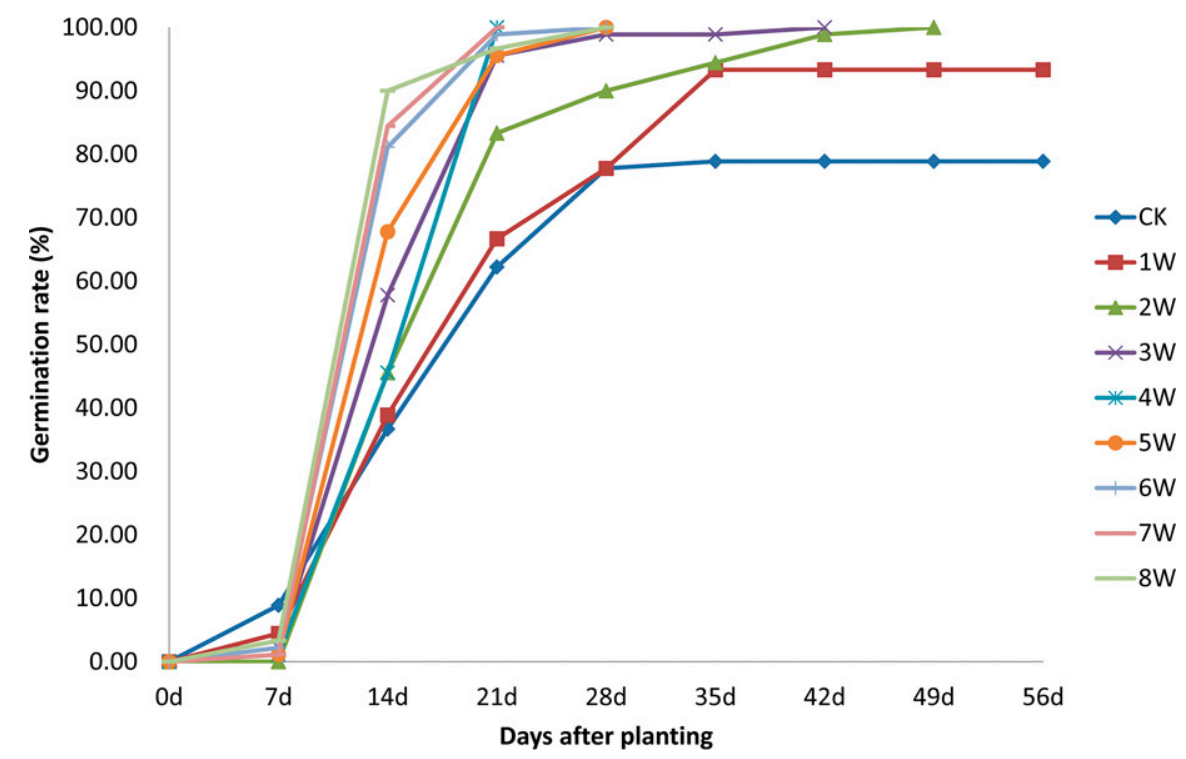

Fig. 1. Effects of $2{ }^{\circ} \mathrm{C}$ treatment on the sprouting rate of bulblets. Values represent the mean of three replicates. Bars indicate SE. CK, bulblets without cold treatment; W, week. 


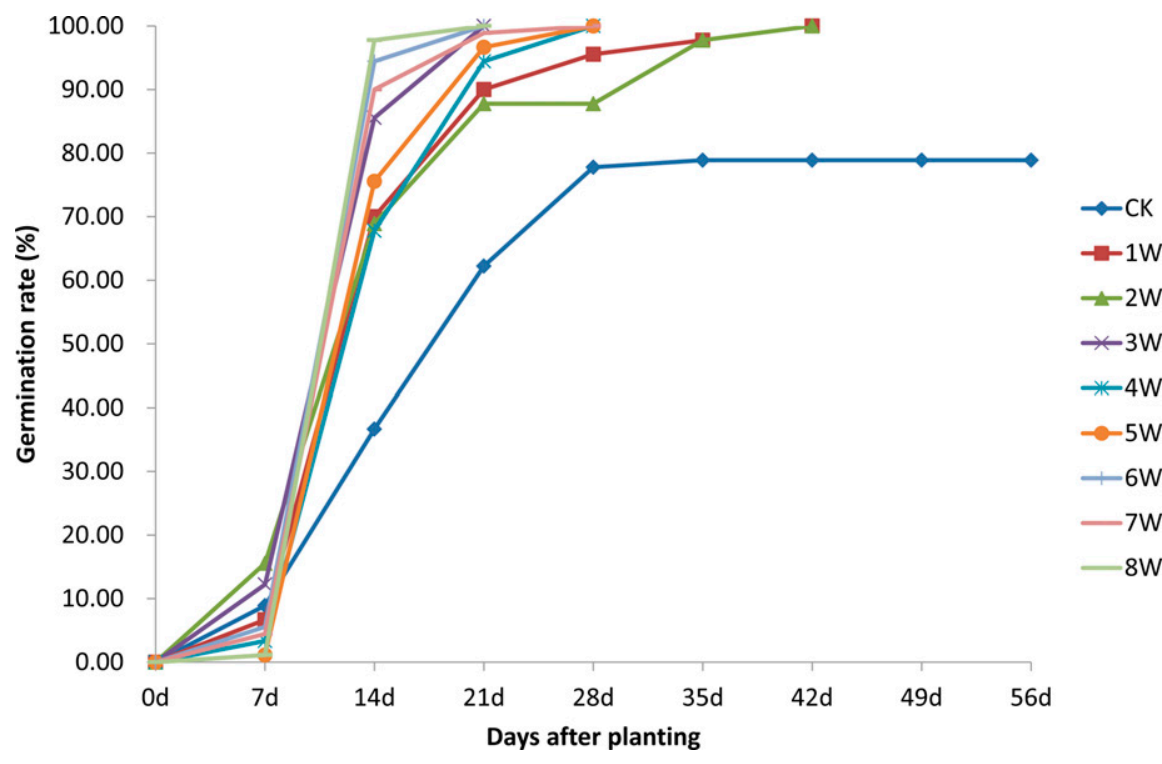

Fig. 2. Effects of $5^{\circ} \mathrm{C}$ treatment on the sprouting rate of bulblets. Values represent the mean of three replicates. Bars indicate SE. CK, bulblets without cold treatment; W, week.

Low-temperature treatment over a certain time was not good for bulb growth. The storage time at the $2{ }^{\circ} \mathrm{C}$ treatment had a significant influence on bulb weight. The postgrowing season bulb weight for bulblets stored at $2^{\circ} \mathrm{C}$ for 3 weeks and 4 weeks $(1.84 \mathrm{~g} /$ bulb and $1.68 \mathrm{~g} /$ bulb) was significantly heavier than that of control bulbs and those treated for longer than 5 weeks. Moreover, storage time also had a dramatic effect on both the weight and circumference of bulblets treated at $5{ }^{\circ} \mathrm{C}$ (Figs. 4 and 5). After a growing season, the bulb weight and circumference of bulblets stored longer than 5 weeks were significantly less than those of bulblets pretreated for 1 to 4 weeks. Maximum bulb weight and circumference were observed for the $5^{\circ} \mathrm{C} / 3$-week $(4.2633 \mathrm{~cm}, 2.0533 \mathrm{~g})$ and $5^{\circ} \mathrm{C} / 4$-week $(4.1233 \mathrm{~cm}, 2.3467 \mathrm{~g})$ treatments. This result suggests that the storage time should

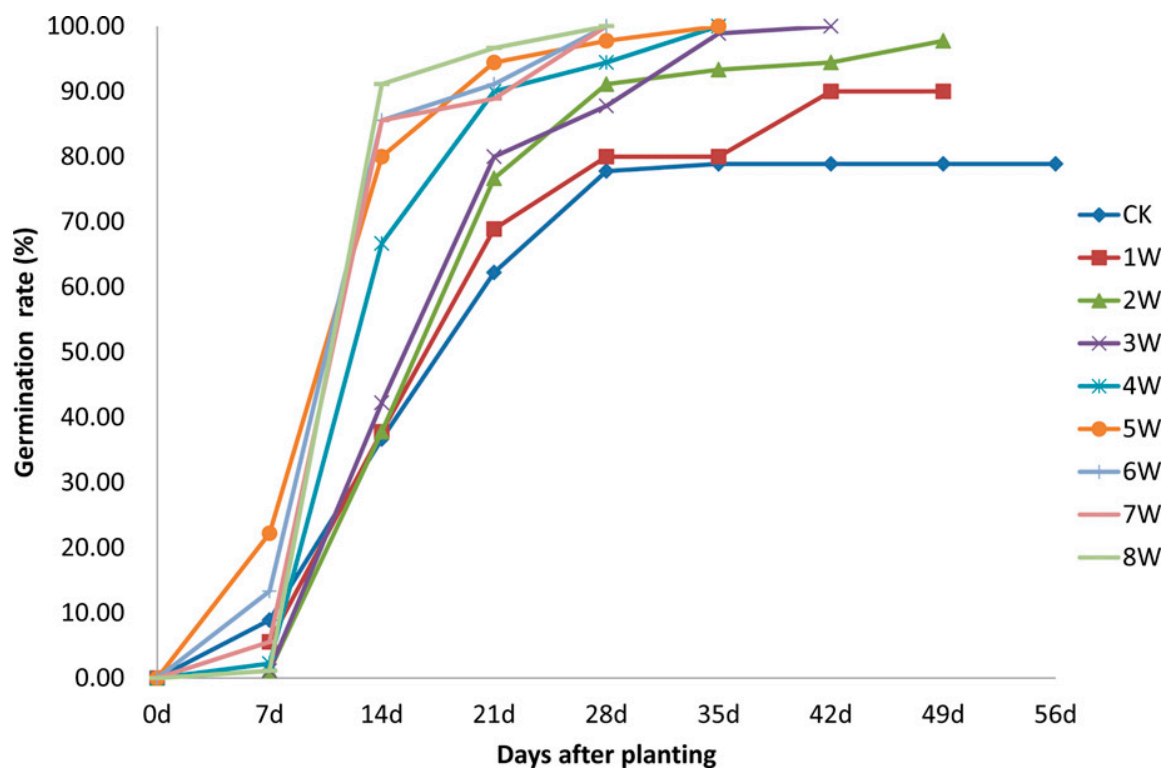

Fig. 3. Effects of $10^{\circ} \mathrm{C}$ treatment on the sprouting rate of bulblets. Values represent the mean of three replicates. Bars indicate SE. CK, bulblets without cold treatment; W, week.
4 weeks. This value was significantly less than that for bulblets at $10^{\circ} \mathrm{C}$ after pretreatment for 3 weeks and 4 weeks. The variation in the starch content in bulblets at 2,5 , and $10^{\circ} \mathrm{C}$ was not significantly different from 5 weeks to 8 weeks. This result indicates that the effect of temperature on the starch content in bulblets diminished gradually over time. Moreover, it was found that the starch content in untreated bulblets broke down slowly and was greater than that in low-temperaturetreated bulblets.

Soluble sugars accumulate as starch breaks down. Soluble sugars provide energy during bulb growth and development. At the same storage time, different temperatures had significantly different effects on the content of soluble sugars. In general, the content of soluble sugars in bulblets stored for 1 to 4 weeks at low temperatures increased rapidly, and the maximum content was observed at 4 weeks. When stored from 2 to 8 weeks, the soluble sugar content of bulblets at 2 and $5^{\circ} \mathrm{C}$ was significantly greater than that of the control and the $10^{\circ} \mathrm{C}$-treated bulblets. The lower the temperature, the faster the conversion of soluble sugars, and the greater the soluble sugar content. It was found that at the eighth week of cold storage, the soluble sugar content in bulblets declined, which may be a result of the bulblets starting to consume soluble sugars. Therefore, for bulblets generated by scale propagation, long storage under low temperature is unfavorable for subsequent growth and development.

\section{Discussion}

Vegetative propagation by scaling is the most cost-efficient and time-saving approach to increase clones of lilies. In the bulb production of Lilium davidii var. unicolor, this technique is widely used among commercial growers because of its high propagation coefficient. Scales are broken off from the basal plate of clean bulbs to permit the formation of bulblets. Direct planting of scales in the field is not recommended because $\approx 17$ weeks are required for bulblet development, during which extreme weather will definitely affect bulblet yield (Austin-McRae, 1998). Moreover, soil moisture is a critical condition for bulblet formation and development, but this is difficult to control in outdoor planting. The incubation method adopted in our study could reduce the propagation cycle to 6 weeks, and the propagation coefficient largely increased. In our previous study, we screened the optimum temperature for scale propagation of $L$. davidii var. unicolor and investigated the effects of plant growth regulators on bulblet development (Tang et al., 2020). After succeeding in obtaining a large number of bulblets, improving the seedling sprouting rate is the key to increasing subsequent bulb production. Low sprouting rates and seedling uniformity were observed when bulblets were planted in the field immediately after incubation. This is because bulblets are generated under relatively high temperatures (25 to $30^{\circ} \mathrm{C}$ ), and they may enter dormancy in 


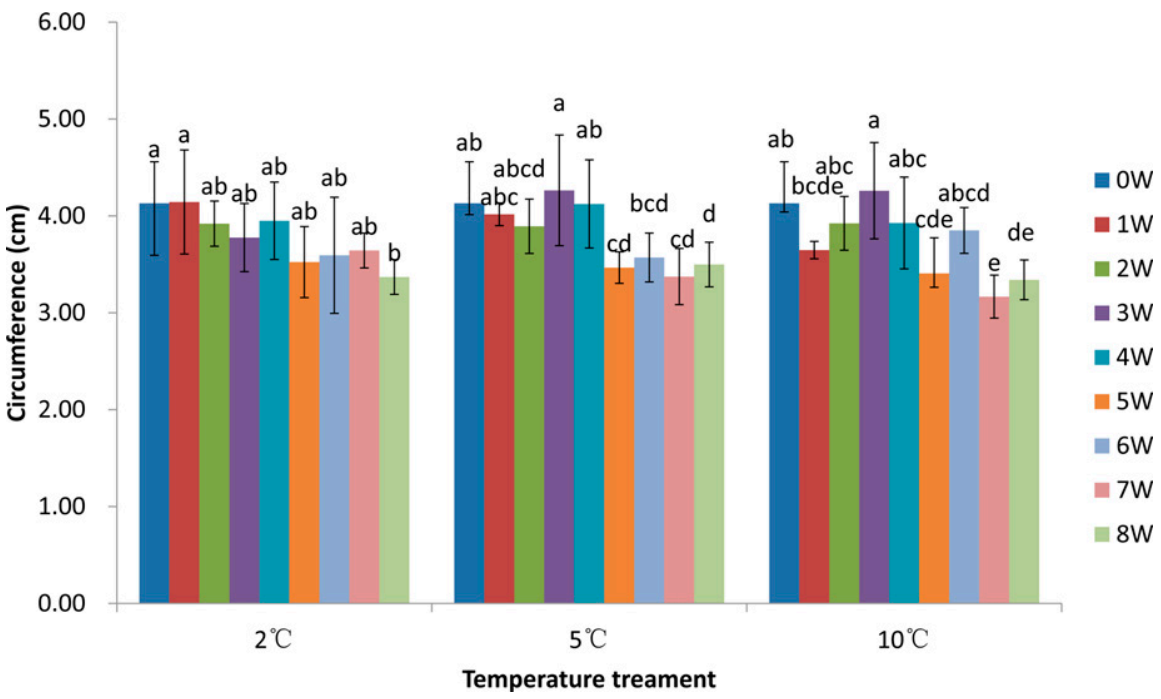

Fig. 4. Effects of low-temperature treatments on the circumference of bulbs. Values represent the mean of three replicates. Bars indicate SE. W, week. The different lowercase letters indicate significant differences at $P<0.05$ level.

response to unsuitable environmental conditions (Delvallée et al., 1990). Dormancy release is one of the most important events in the production of lilies. Although basic patterns for breaking dormancy have been proposed, the procedures are not exactly the same in different species (Dole, 2003). Dormancy can be broken by low temperatures, plant growth regulators, and other treatments, such as nitric oxide and low oxygen (Amaki and Amaki, 2005; Jásik and de Klerk, 2006; Niimi et al., 1988; Niu et al., 2015; Situma et al., 2015). Low temperature is the most common way to break dormancy for geophytes. The period of storage at low temperature affects not only the number of sprouting bulblets, but also the time it takes for the seedling to emerge after planting in the field. The results of our study show that low temperature has a significant effect on enhancing the sprouting percentage of $L$. davidii bulblets. A constant

$5{ }^{\circ} \mathrm{C}$ treatment for 3 weeks is the best selection for bulblet pretreatment before planting, at which only $21 \mathrm{~d}$ are needed for sprouting of all bulblets. As an alternative, storage at $2{ }^{\circ} \mathrm{C}$ for 4 weeks is also effective in promoting seedling emergence. Cold treatment longer than 5 weeks is not helpful for increasing the sprouting of bulblets. Instead, the bulb weight and circumference are dramatically less than those stored for up to 4 weeks.

The dormancy of many plants can be broken by low-temperature treatments. For $L$. davidii, Sun et al. (2004) found that after 101 d of storage at $2{ }^{\circ} \mathrm{C}$, all bulbs sprouted within 20 d. This presents a difference between mature bulbs and bulblets. In our study, bulblets only needed 4 weeks of $2{ }^{\circ} \mathrm{C}$ treatment to achieve $100 \%$ sprouting. Previous studies have been performed on the dormancy release of bulblets regenerated on scales in vitro, but no study has been reported for bulblets

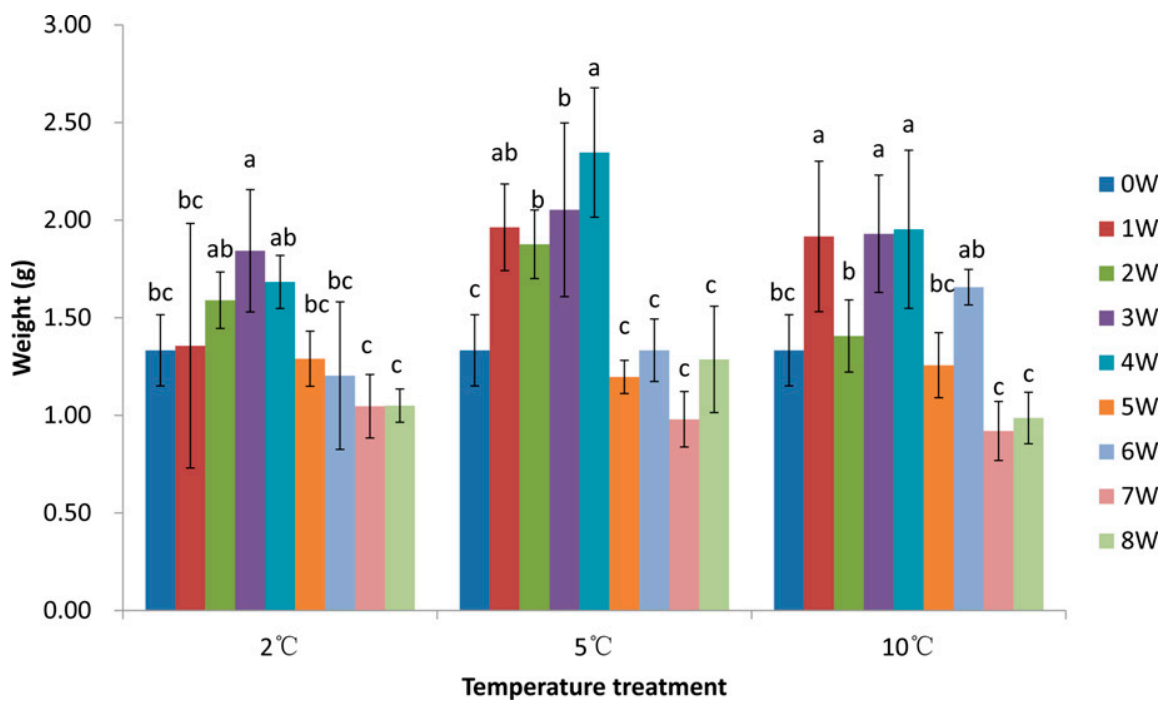

Fig. 5. Effects of low-temperature treatments on the weight of bulbs. Values represent the mean of three replicates. Bars indicate SE. W, week. The different lowercase letters indicate significant differences at $P<0.05$ level. produced by scale propagation. de Klerk (2009) found that $9^{\circ} \mathrm{C}$ was the optimal temperature for breaking dormancy in lily bulblets obtained by micropropagation. Storage for several weeks at $5^{\circ} \mathrm{C}$ promoted dormancy release in bulblets that regenerated from scale explants of $L$. speciosum (Langens-Gerrits et al., 2003). For Asian lilies, storage at a temperature ranging from 1 to $10^{\circ} \mathrm{C}$ was effective for breaking the dormancy of bulblets regenerated in vitro (Shin et al., 2002). However, shoot emergence was not influenced by temperature treatments given to bulbils of Lilium $\times$ elegans Thunb. (Suh and Roh, 2014). The genus Lilium has abundant species/varieties, and it can be seen that the temperature and storage time required for dormancy release vary across species, varieties, organs, and stages of growth.

The bulb is the vegetative storage organ of lilies, in which starch is the major reserve carbohydrate. Exposure of bulbs to low temperatures induces starch hydrolysis accompanied by the accumulation of soluble sugars, and energy is provided for bulb dormancy release (Miller and Langhans, 1990; Xu et al., 2006). The regulatory pathways of carbohydrate metabolism are activated, and carbohydrates present a positive relationship with dormancy release in lily bulbs (Wang et al., 2018; Zhang et al., 2011). In our study, during the storage of bulblets at low temperatures, starch breakdown coincided with an increase in soluble sugars (Fig. 6). Storage at 2 and $5{ }^{\circ} \mathrm{C}$ resulted in more dramatic alterations in bulb carbohydrates than storage at $10^{\circ} \mathrm{C}$. Large changes in carbohydrates occurred during the first 4 weeks of storage. The effect of low temperatures on carbohydrates in bulblets diminished gradually over time. Long storage under low temperatures is unfavorable for the subsequent growth of seedlings because the bulbs start consuming carbohydrates during the later stage of storage. During dormancy breaking, similar carbohydrate changes were observed in bulbs of $L$. pumilum (Liu et al., 2016) and tulip (Kamenetsky et al., 2003), in tubers of potato (Claassens, 2002), and in flower buds and shoots of Japanese pear (Ito et al., 2012). The changes in carbohydrates during dormancy release may affect not only the leaf emergence of bulblets, but also the subsequent growth of bulbs. Starch hydrolysis and soluble sugar accumulation occurred mainly in the 0 - to 4week cold treatments, and the changes were no longer significant after 4 weeks. Excellent sprouting of bulblets was observed in cold treatments with a storage time of 3 to 4 weeks. Moreover, after a growing season, the largest bulbs were also obtained from bulblets that were stored for 3 weeks and 4 weeks at different low temperatures. Reserves of a certain amount of carbohydrates are important in the development of organs such as bulbs and tubers (Burton et al., 1992; Fernie and Willmitzer, 2001; Geigenberger, 2003). It was observed in Tulipa edulis that soluble sugar levels declined whereas starch and protein accumulated in the process of stolon development into a new bulb (Miao et al., 2016). 


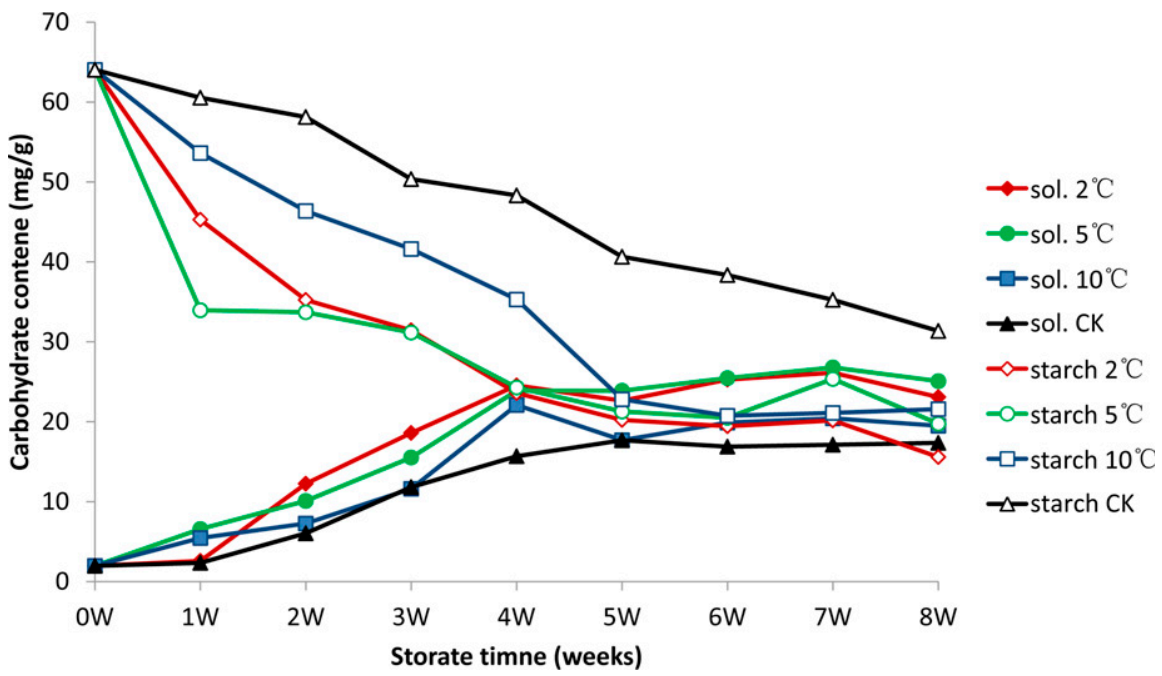

Fig. 6. Variation in starch and soluble sugar (sol.) concentrations in bulblets during storage at low temperatures $\left(2,5\right.$, and $\left.10^{\circ} \mathrm{C}\right)$. Values represent the mean of three replicates. CK, bulblets without cold treatment; W, week.

During tuber development in potato and sweetpotato, large amounts of carbohydrate reserves, such as starch and storage proteins, accumulate in the tubers (Firon et al., 2013; Kloosterman et al., 2008). Thus, excessively long storage is not good for bulb growth, possibly because of the overconsumption of carbohydrates in the bulblets.

In conclusion, to obtain the largest sprouting rate in the shortest time period and produce the largest bulbs after a growing season, the best temperature treatment for bulblets of $L$. davidii var. unicolor generated by scale propagation is $5^{\circ} \mathrm{C}$ for 3 to 4 weeks. The results of our study provide important information for accelerating the scale propagation of $L$. davidii var. unicolor and maximizing bulb yield.

\section{Literature Cited}

Amaki, W. and W. Amaki. 2005. Dormancy release of easter lily bulb by low $\mathrm{O}_{2}$ concentration treatments. Acta Hort. 673:591-594, doi: 10.17660/ActaHortic.2005.673.81.

Austin-McRae, E. 1998. Lilies: A guide for growers and collectors. Timber Press, Portland, OR.

Burton, W.G., A. van Es, and K.J. Hartmans. 1992. The physics and physiology of storage, $\mathrm{p}$. 608-727. In: P.M. Harris (ed.). The potato crop. Springer, Dordrecht, the Netherlands, doi: $10.1007 / 978$ 94-011-2340-2 14

Claassens, M.M.J. 2002. Carbohydrate metabolism during potato tuber dormancy and sprouting. Wageningen University, Wageningen, the Netherlands, PhD Diss.

de Klerk, G.J. 2009. A cold treatment promotes both sprouting and sink strength of lily bulblets. Propag. Ornam. Plants 9:102-106, doi: 0.1016/j.postharvbio.2009.01.006.

de Klerk, G.J. and A. Paffen. 1995. The effects of environmental conditions on sprouting of micropropagated lily bulblets with various levels of dormancy. Plant Biol. 44:33-39, doi: 10.1111/j.1438-8677.1995.tb00766.x.

Delvallée, I., A. Paffen, and G.J. de Klerk. 1990. The development of dormancy in bulblets of Lilium speciosum generated in vitro: II. The effect of temperature. Physiol. Plant. 80:431-436, doi: 10.1111/j.1399-3054.1990.tb00063.x.

Djilianov, D., M.M. Gerrits, A. Ivanova, H.A. van Onckelen, and G.J. de Klerk. 1994. ABA content and sensitivity during the development of dormancy in lily bulblets regenerated in vitro. Physiol. Plant. 91:639-644, doi: 10.1111/j.13993054.1994.tb02999.x.

Dole, J.M. 2003. Research approaches for determining cold requirements for forcing and flowering of geophytes. HortScience 38:341-346, doi: 10.21273/HORTSCI.38.3.341.

Erwin, J.E. and G. Engelen-Eigles. 1998. Influence of simulated shipping and rooting temperature and production year on easter lily (Lilium longiflorum Thunb.) development. J. Amer. Soc. Hort. Sci. 123:230-233, doi: 10.1023/A:1008627419 450.

Fernie, A.R. and L. Willmitzer. 2001. Molecular and biochemical triggers of potato tuber development. Plant Physiol. 127:1459-1465, doi: 10.1104/pp.010764.

Firon, N., D. Labonte, A. Villordon, Y. Kfir, J. Solis, E. Lapis, T.S. Perlman, A. Doron-Faigenboim, A. Hetzroni, L. Althan, and L.A. Nadir. 2013. Transcriptional profiling of sweetpotato (Ipomoea batatas) roots indicates downregulation of lignin biosynthesis and up-regulation of starch biosynthesis at an early stage of storage root formation. BMC Genomics 14:460, doi: 10.1186/1471-2164-14-460.

Geigenberger, P. 2003. Regulation of sucrose to starch conversion in growing potato tubers. $\mathrm{J}$. Expt. Bot. 54:457-465, doi: 10.1093/jxb/erg074.

Ito, A., D. Sakamoto, and T. Moriguchi. 2012. Carbohydrate metabolism and its possible roles in endodormancy transition in Japanese pear. Scientia Hort. 144:187-194, doi: 10.1016/j. scienta.2012.07.009.

Jan, B. and M. Roel. 1993. An improved colorimetric method to quantify sugar content of plant tissue. J. Expt. Bot. 44:1627-1629, doi: 10.1093/jxb/44.10.1627.

Jásik, J. and G.J. de Klerk. 2006. Effect of methyl jasmonate on morphology and dormancy development in lily bulblets regenerated in vitro. J. Plant Growth Regulat. 25:45-51, doi: 10.1007/ s00344-005-0048-4.

Jia, R., N. Tang, X. Ju, D.C. Tang, and C.N. Lü. 2020. Effects of temperature treatments on bulblet propagation of Lilium davidii var. unicolor scales in peatmoss substrate. Guihaia, doi: 10.11931/guihaia.gxzw201908013.

Kamenetsky, R., H. Zemah, A.P. Ranwala, F. Vergeldt, N.K. Ranwala, W.B. Miller, H.V. As, and P. Bendel. 2003. Water status and carbohydrate pools in tulip bulbs during dormancy release. New Phytol. 158:109-118, doi: 10.1046 j.1469-8137.2003.00719.x.

Kawarabayashi, W. 2015. Influence of temperature on seed germination and seedling-bulb enlargement, and growth process of bulb in Lilium candidum L. Hort. Res. 14:179-189, doi: 10.2503/hrj.14.179.

Kloosterman, B., D. de Koeyer, R. Griffiths, B. Flinn, B. Steuernagel, U. Scholz, S. Sonnewald, U. Sonnewald, G.J. Bryan, S. Prat, Z. Bánfalvi, J.P. Hammond, P. Geigenberger, K.L. Nielsen, R.G.F. Visser, and C.W.B. Bachem. 2008. Genes driving potato tuber initiation and growth: Identification based on transcriptional changes using the POCI array. Funct. Integr. Genomics 8:329-340, doi: 10.1007/s10142-008-0083-x.

Langens-Gerrits, M.M., W.B.M. Miller, A.F Croes, and G.J. de Klerk. 2003. Effect of low temperature on dormancy breaking and growth after planting in lily bulblets regenerated in vitro. Plant Growth Regulat. 40:267-275, doi: 10.1023/A:1025018728178.

Lee, J.S., Y.A. Kim, and H.J. Wang. 1996. Effect of bulb vernalization on the growth and flowering of Asiatic hybrid lily. Acta Hort. 414:229-234, doi: 10.17660/ActaHortic.1996.414.27.

Lee, E., N. Yun, Y.P. Jang, and J. Kim. 2013. Lilium lancifolium Thunb. extract attenuates pulmonary inflammation and air space enlargement in a cigarette smoke-exposed mouse model. J. Ethnopharmacol. 149:148-156, doi: 10.1016/j.jep. 2013.06.014.

Li, Y., H. Wang, W. Zhang, H. Wu, and Z. Wang. 2021. Evaluation of nutrition components in Lanzhou lily bulb by confocal Raman microscopy. Spectrochim. Acta A Mol. Biomol. Spectrosc. 244:118837, doi: 10.1016/j.saa.2020.118837.

Liu, F., Y.W. Chen, D.D. Li, H. Lian, X. Wu, J. Yang, Y.Q. Li, S.F. Xie, and X.W. Chen. 2016. Changes in carbohydrate status and related enzymes of Lilium pumilum bulbs during breaking dormancy under refrigerated conditions. Acta Prataculturae Sinica 25:60-68, doi: $10.11686 /$ cyxb2015343.

Liu, X., Q. Wang, J. Gu, and Y. Lü. 2014. Vernalization of Oriental hybrid lily 'Sorbonne': Changes in physiology metabolic activity and molecular mechanism. Mol. Biol. Rep. 41:6619-6634, doi: 10.1007/s11033-014-3545-3.

Marinangeli, P.A., L.F. Hernández, C.P. Pellegrini, and N.R. Curvetto. 2003. Bulblet differentiation after scale propagation of Lilium longiflorum. J. Amer. Soc. Hort. Sci. 128:324-329, doi: 10.21273/jashs.128.3.0324.

Matsuo, E., M. Matsuzawa, Y. Sakata, and K. Arisumi. 1989. Asexual propagation of variegated $\mathrm{Lil}$ ium longiflorum 'Chotaro'. Scientia Hort. 39:349-354, doi: 10.1016/0304-4238(89)90128-3.

Matsuo, E. and J.M. van Tuyl. 1984. Effect of bulb storage temperature on leaf emergence and plant development during scale propagation of Lilium longiflorum 'White American'. Scientia Hort. 24:59-66, doi: 10.1016/0304-4238(84) 90008-6.

Miao, Y., Z. Zhu, Q. Guo, X. Yang, L. Liu, Y. Sun, and C. Wang. 2016. Dynamic changes in carbohydrate metabolism and endogenous hormones during Tulipa edulis stolon development into a new bulb. J. Plant Biol. 59:121-132, doi: 10.1007/s12374-016-0456-y. 
Miller, W.B. and R.W. Langhans. 1990. Low temperature alters carbohydrate metabolism in easter lily bulbs. HortScience 25:463-465, doi: 10.21273/HORTSCI.25.4.463.

Niimi, Y., Y. Endo, and E. Arisaka. 1988. Effects of chilling- and $\mathrm{GA}_{3}$-treatments on breaking dormancy in Lilium rubellum Baker bulblets cultured in vitro. Engei Gakkai Zasshi 57:250-257, doi: 10.2503/jjshs.57.250.

Niu, L., B. Li, W. Liao, Y. Zhu, M. Wang, X. Jin, and Q. Xu. 2015. Effect of nitric oxide on dormancy release in bulbs of Oriental lily (Lilium orientalis) 'Siberia'. J. Hort. Sci. Biotechnol. 90:594-598, doi: 10.1080/14620316.2015.11668720.

Shin, K.S., D. Chakrabarty, and K.Y. Paek. 2002. Sprouting rate, change of carbohydrate contents and related enzymes during cold treatment of lily bulblets regenerated in vitro. Scientia Hort. 96:195-204, doi: 10.1016/S0304-4238(02) 00087-0.

Situma, M.N., M. Mwangi, and R.M.S. Mulwa 2015. Effects of benzyl adenine and gibberellic acid pre-treatments on dormancy release, flowering time and multiplication of oriental lily
(Lilium longiflorum) bulbs. J. Appl. Hort. 17:26-30, doi: 10.37855/jah.2015.v17i01.06.

Suh, J.K. and M.S. Roh. 2014. New technique for cut flower production from bulbils of the Asiatic hybrid lily (Lilium $\times$ elegans Thunb.). Scientia Hort. 165:374-383, doi: 10.1016/j. scienta.2013.11.012.

Sun, H., T. Li, and Y. Li. 2004. Starch metabolism and sprouting of bulb in Lilium davidii var. unicolor stored at different cold temperatures. Acta Hort. Sinica 31:337-342, doi: 10.1300/ J064v24n01_09.

Tang, N., X. Ju, Y. Hu, R. Jia, and D. Tang. 2020. Effects of temperature and plant growth regulators on the scale propagation of Lilium davidii var. unicolor. HortScience 55:1-6, doi: 10.212 73/HORTSCI14916-20.

Wang, W., X. Su, Z. Tian, Y. Liu, Y. Zhou, and M. He. 2018. Transcriptome profiling provides insights into dormancy release during cold storage of Lilium pumilum. BMC Genomics 19:196, doi: 10.1186/s12864-018-4536-x.

Xu, R.Y., Y. Niimi, and D.S. Han. 2006. Changes in endogenous abscisic acid and soluble sugars levels during dormancy-release in bulbs of $\mathrm{Lil}$ ium rubellum. Scientia Hort. 111:68-72, doi: 10.1016/j.scienta.2006.08.004.

You, X.J., C.Y. Xie, K.L. Liu, and Z.X. Gu. 2010. Isolation of non-starch polysaccharides from bulb of tiger lily (Lilium lancifolium Thunb.) with fermentation of Saccharomyces cerevisiae. Carbohydr. Polym. 81:35-40, doi: 10.1016/j. carbpol.2010.01.051.

Zhang, J., Y. Gao, X. Zhou, L. Hu, and T. Xie. 2010. Chemical characterisation of polysaccharides from Lilium davidii. Nat. Prod. Res. 24:357-369, doi: 10.1080/14786410903182212.

Zhang, J., Z.K. Xie, Y.J. Wang, and L.P. An. 2011. Changes in carbohydrate metabolism and bulb growth as induced by low-temperature release of dormancy in lily bulbs. Philipp. Agr. 94:149-154, doi: 10.1016/j.njas.2011.03.001.

Zhou, Y., W. Wang, L. Yang, X. Su, and M. He. 2021. Identification and expression analysis of microRNAs in response to dormancy release during cold storage of Lilium pumilum bulbs. J. Plant Growth Regulat. 40:388-404, doi: 10.1007/s00344-020-10108-1. 